\title{
Pubertal arrest and hypoplastic reproductive organs in a 22-year-old female with untreated prolactinoma.
}

\author{
Dr Oyindamola Awofisoye \& Kingsley Iseko.
}

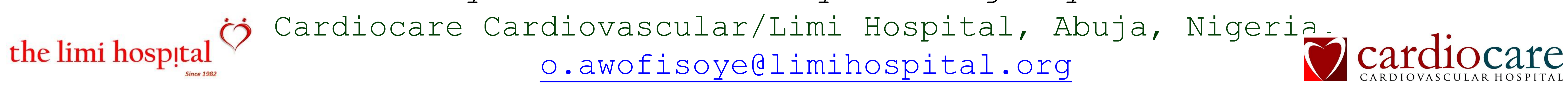

\section{Introduction}

Pubertal arrest caused by prolactinoma is a rare condition characterised by failure to attain menstruation after the onset of thelarche and pubarche. Previously reported cases involved younger females, who typically received prompt treatment with complete resolution. This report describes a 22-year-old woman with arrested puberty, who was earlier diagnosed with a prolactinoma at the age of 16 .

\section{Case:}

A 22-year-old woman presented to our facility with primary amenorrhea.

She was diagnosed with a prolactinoma elsewhere at the age of 16 , when she presented with headaches, bitemporal hemianopsia and primary amenorrhea (no galactorrhea).

She attained pubarche and telarche at 11 and 14 years respectively.

Investigations then revealed panhypopituitarism (table) and a 22mm pituitary mass.

Carbegoline and Levothyroxine were prescribed to her then, which she used for a year but stopped when her headaches resolved. She did not go for follow up because of financial limitations.

She presented to us with recurrence of headaches and persistence of amenorrhea.

She had no galactorrhea, visual field defects, hot flushes, virilisation or hirsutism.
She weighed $62 \mathrm{~kg}$ and her height was $1.65 \mathrm{~m}(\mathrm{BMI}=22.7)$. Her breasts were at Tanner stage 4 and pubic hair was at Tanner stage 5.

Her external genitalia appeared normal on examination. Her hormonal profile revealed persistent of panhypopituitarism (table).

Growth hormone assay and MRI were not repeated due to financial limitations.

Pelvic ultrasound scan showed hypoplastic uterus (length= $4.1 \mathrm{~cm}$ ) and ovaries (volume $=4 \mathrm{ml}$ ) - this is about the size expected in Tanner stage 3.

She was re-commenced on carbegoline, hydrocortisone and levothyroxine.

Repeat hormonal profile after 6 months showed improvement of prolactin and thyroid function (table). Oestrogen however remained low despite normal progesterone and gonadotropins. She remained amenorrheic at 11 months after recommencing treatment.

\begin{tabular}{|c|c|c|c|c|}
\hline Hormone & 6 years priork & At presentation & 6 months after & Reference \\
\hline Prolactin & $144 \mathrm{ng} / \mathrm{ml}(3.2-20) \uparrow$ & $109 \mathrm{ng} / \mathrm{ml} \uparrow$ & 19.0 & $(1.2-19.5)$ \\
\hline FSH & $1.6 \mathrm{IU} / \mathrm{L}(1.8-8.5) \downarrow$ & $16.2 \mathrm{IU} / \mathrm{L}$ & 11.8 & $(3-12,8-22)$ \\
\hline LH & $1.1 \mathrm{mlU} / \mathrm{ml}(1.5-5.5) \downarrow$ & $3.0 \mathrm{mlU} / \mathrm{ml}$ & 2.2 & $(0.5-10,18-61)$ \\
\hline $\mid G=-1$ & $180 \mathrm{ng} / \mathrm{ml}(236-810) \downarrow$ & - & - & - \\
\hline TSH & $0.6 \mathrm{mlU} / \mathrm{ml}(0.5-4.3)$ & $1.0 \mathrm{mlU} / \mathrm{ml}$ & - & $(0.4-6.1)$ \\
\hline Free T4 & $0.6 \mathrm{ng} / \mathrm{ml}(0.8-2.60 \downarrow$ & $0.7 \mathrm{ng} / \mathrm{ml} \downarrow$ & 1.42 & $(0.8-2.24)$ \\
\hline Oestrogen & - & $20.6 \mathrm{pg} / \mathrm{ml} \downarrow$ & $22.4 \downarrow$ & $(25-420)$ \\
\hline Progesterone & - & $2.9 \mathrm{pg} / \mathrm{ml}$ & $1.5 \downarrow$ & $(0.15-1.40,2.0-25.0)$ \\
\hline Cortisol (8am) & $4.88 \mathrm{ug} / \mathrm{dl}(5-21) \downarrow$ & $5.31 \mathrm{ug} / \mathrm{dl} \downarrow$ & - & $(6.0-18.4)$ \\
\hline
\end{tabular}

\section{Discussion:}

Hyperprolactinemia is a rare cause of amenorrhea in adolescence, reported to be associated with less than $1 \%$ of cases of primary amenorrhea in a series ${ }^{[1]}$. Prolactinomas occurring at puberty can manifest as pubertal arrest as in this case. Despite attaining telarche, adrenarche and pubertal growth, our patient failed to attain menarche. Pubertal arrest in this case is predominantly due to hyperprolactinemia, which inhibits optimal functioning of the hypothalamic-pituitary gonadal axis likely via reduced pulsatility of $\mathrm{GnRH}$. In this case however, low gonadotropins, adrenal and thyroid insufficiencies are likely contributory.

Hypoplasia of the internal reproductive organs is a recognized consequence of pubertal arrest. Hypoplasia in the context of hyperprolactinemia has been described at younger ages ${ }^{[2,3]}$. The uterus normally increases in size during puberty in response to oestrogen stimulation, from about $30 \mathrm{~mm}$ to $60 \mathrm{~mm}$. The ovaries also increase in size under gonadotrophin influence. Untreated hyperprolactinemia, via effects on the gonadotropins - affects oestrogen levels and thus reduced uterine/ovarian size. However, the uterine/ovarian size appeared smaller than what is expected for her Tanner stage. It has been suggested that the uterus requires higher levels of oestrogen for maturation compared to the breast and other peripheral tissues ${ }^{[3]}$. The direct effect of hypogonadotrophic hypogonadism at critical stages of puberty, with low GH and hypothyroidism are also contributory.

Since recommencement of dopamine agonist, the patient is yet to attain her menstruation after 11 months. There are reports of resolution of pubertal arrest with catch-up growth of reproductive organs at younger ages ${ }^{[2,3]}$. It is uncertain whether she would attain menstruation and fertility considering the prolonged course through the critical adolescence period. There may be a role for pulsed $\mathrm{GnRH}$ and/or oestrogen therapy if amenorrhea persists despite optimization of hormonal levels.

It is important to promptly evaluate, educate and treat persons with hyperprolactinemia related pubertal disorders to prevent persistent dysfunction of the pituitary-gonadal axis. 